\title{
Comportamento nutricional, produção e qualidade de frutas de tangerineira 'Ponkan' aplicando granulado bioclástico
}

\author{
Nutritional behavior, production and fruit quality of 'Ponkan' \\ mandarin trees applying calcified seaweed
}

\author{
Rodrigo Amato Moreira ${ }^{1 *}$; José Darlan Ramos²; Fabio Oseias dos Reis Silva'; \\ Thatiane Padilha de Menezes ${ }^{1}$; Paulo César de Melo²
}

\begin{abstract}
Resumo
O trabalho foi realizado com o objetivo de avaliar o comportamento nutricional, a produção e qualidade de frutas de tangerineira 'Ponkan' utilizando granulado bioclástico. O experimento foi conduzido em pomar comercial não irrigado, localizado no município de Perdões, região Sul de Minas Gerais, Brasil. As tangerineiras 'Ponkan' utilizadas estavam enxertadas sobre limoeiro 'Cravo', com treze anos de idade, cultivadas no espaçamento $6 \mathrm{~m}$ x $3 \mathrm{~m}$. O delineamento experimental foi em blocos casualizados, com parcela subdividida no tempo, sendo a parcela quatro doses de granulado bioclástico $(0,0 ; 0,3$; 0,6 e $\left.1,2 \mathrm{~kg} \mathrm{planta}^{-1}\right)$ e a subparcela os dois anos de avaliação (2010 e 2011). Foram utilizadas seis repetições e quatro plantas por parcela. Nas épocas de colheita foram retiradas amostras foliares em ramos produtivos para quantificar os teores de nutrientes. Também foram avaliados: produção, diâmetro transversal, diâmetro longitudinal, massa, acidez titulável, teores de sólidos solúveis e ratio das frutas. A aplicação de granulado bioclástico aumentou os teores foliares de N, P, Ca e Mg na época de colheita. Os teores de K nas folhas das tangerineiras 'Ponkan' na época de colheita reduziram com o aumento da dose de granulado bioclástico por planta. A dose de $0,8 \mathrm{~kg}$ de granulado bioclástico por planta favoreceu a produção e melhorou a qualidade das frutas de tangerineira 'Ponkan'.
\end{abstract}

Palavras-chave: Citrus reticulata Blanco, Lithothamnium, nutrientes

\begin{abstract}
The present study was performed to evaluate the nutritional behavior, production and quality of fruits of 'Ponkan' mandarin trees using calcified seaweed. It was conducted in unirrigated orchard located in Perdões, the southern region of Minas Gerais, Brazil. The 'Ponkan' mandarin used were grafted on 'Rangpur' lime, thirteen years old, cultivated with spacing of $6 \mathrm{~m}$ x $3 \mathrm{~m}$. The experimental design was the randomized block design with split plot in time, with four rates of calcified seaweed $(0.0,0.3$, 0.6 and $\left.1.2 \mathrm{~kg} \mathrm{plant}^{-1}\right)$ in the plot, and the two years of assessment (2010 and 2011) in the subplot. At harvest, leaves samples were collected from productive branches for analysis of nutrients. Production, transverse diameter, longitudinal diameter, mass, titatrable acidity, soluble solids and soluble solids/ titatrable acidity ratio of fruits were evaluated. The application of calcified seaweed increased the leaf levels of N, P, Ca and Mg at harvest. The level of K in the leaves of 'Ponkan' mandarin trees at harvest decreased with the rates of calcified seaweed per plant. The calcified seaweed rate of $0.8 \mathrm{~kg}$ per plant favored the production and improved the quality of 'Ponkan' mandarin fruits.
\end{abstract}

Key words: Citrus reticulata Blanco, Lithothamnium, nutrients

\footnotetext{
${ }^{1}$ Discentes do Curso de Doutorado em Fitotecnia, Universidade Federal de Lavras, UFLA, Lavras, MG. E-mail: amatomoreira@ yahoo.com.br; foseias@yahoo.com.br; thatiagro@yahoo.com.br

2 Profs., Dept ${ }^{\circ}$ de Agricultura, UFLA, Lavras, MG. E-mail: darlan@dag.ufla.br; pcmelo@dag.ufla.br

* Autor para correspondência
} 


\section{Introdução}

O cultivo de tangerineiras desempenha importante papel econômico e social, pois dependendo da forma de manejo das plantas e do grau de mecanização dos pomares, pode-se considerar a necessidade de uma pessoa para o cultivo de dois hectares (KOLLER, 2009). Ao considerar que a área colhida de tangerinas no Brasil está próxima a 54.000 hectares (AGRIANUAL, 2011), estima-se que a cultura proporcione 27.000 empregos diretos, com pessoas atuando no meio rural na produção de tangerinas. Dentre essas tangerineiras, a cultivar 'Pokan' destaca-se com maior área de cultivo e com a produção bem aceita no mercado de frutas frescas devido as suas características internas e externas (RAMOS et al., 2009; CRUZ; MOREIRA, 2012).

$\mathrm{Na}$ produção de citros ocorre exportação de nutrientes pelas frutas e, por conseguinte, diminuição dos teores de nutrientes no solo (FIDALSKI; AULER, 2008), aliado a isso, a maioria das áreas cultivadas no Sudeste do Brasil apresenta solos com acidez elevada, alumínio em níveis tóxicos, baixa capacidade de retenção de cátions e baixos teores de bases, que podem afetar a produção e influenciar a qualidade das frutas de tangerineira 'Ponkan'. Nesse sentido, a utilização de granulados bioclásticos, que são constituídos por algas calcárias Lithothamnium $s p$., pode contribuir para a melhoria dos atributos físicos, químicos e microbiológicos do solo (DIAS, 2000), disponibilizando nutrientes às plantas, assim como auxiliar na correção da acidez do solo (MELO; FURTINI NETO, 2003).

Plantas cítricas manejadas com adubações químicas e com resíduo orgânico resultaram em benefícios na nutrição, produtividade e qualidade de frutas (MATTOS JÚNIOR et al., 2004; SANTOS et al., 2011; QUAGGIO; MATTOS JÚNIOR; BOARETTO, 2011). No entanto, ainda são escassos experimentos em campo que avaliem esses fatores com a aplicação de produtos com algas calcárias em pomares cítricos. Alguns trabalhos realizados em ambiente protegido com adição de granulado bioclástico ao substrato de cultivo mostraram resultados satisfatórios no crescimento de mudas, a exemplo de citrumeleiro 'Swingle' (ARAÚJO et al., 2007), de tangerineira 'Cleópatra' (CRUZ et al., 2008), de mamoeiro (HAFLE et al., 2009) e de maracujazeiro (SOUZA et al., 2009). Em pesquisa a campo, Moreira et al. (2011a,b) constaram maior crescimento inicial de mudas e melhoria da qualidade de frutas de pitaia utilizando o granulado bioclástico incorporado à adubação orgânica.

Diante do exposto, o experimento foi realizado com o objetivo de avaliar o comportamento nutricional, a produção e a qualidade das frutas de tangerineira 'Ponkan' aplicando granulado bioclástico.

\section{Material e Métodos}

O trabalho foi realizado em pomar comercial não irrigado, localizado no município de Perdões, $21^{\circ} 05^{\prime} 27$ “(Sul) e 45 05' 27” (Oeste), região Sul de Minas Gerais, no período de dezembro de 2009 a junho de 2011. Segundo a classificação de Köppen, o tipo climático da região é Cwa, com verões quentes e úmidos, e invernos secos e frios. Os dados mensais de temperaturas máxima, mínima e média, umidade relativa e precipitação foram registrados durante o período experimental (Figura 1).

As tangerineiras 'Ponkan' (Citrus reticulata Blanco) utilizadas estavam enxertadas sobre limoeiro 'Cravo'(Citrus limonia Osbeck), com treze anos de idade, cultivadas no espaçamento $6 \mathrm{~m} \mathrm{x} 3$ m, em solo classificado como Argissolo Amarelo Distrófico típico, contendo $59 \%$ de argila, $28 \%$ de silte e $13 \%$ de areia, com os atributos químicos antes da aplicação dos tratamentos, referente a junho de 2009, apresentados na tabela 1 . 
Figura 1. Dados mensais de precipitação $(\mathrm{mm})$, temperatura máxima $\left({ }^{\circ} \mathrm{C}\right)$, temperatura mínima $\left({ }^{\circ} \mathrm{C}\right)$, temperatura média $\left({ }^{\circ} \mathrm{C}\right)$ e umidade relativa $(\%)$ durante o período experimental na região de Perdões, MG.

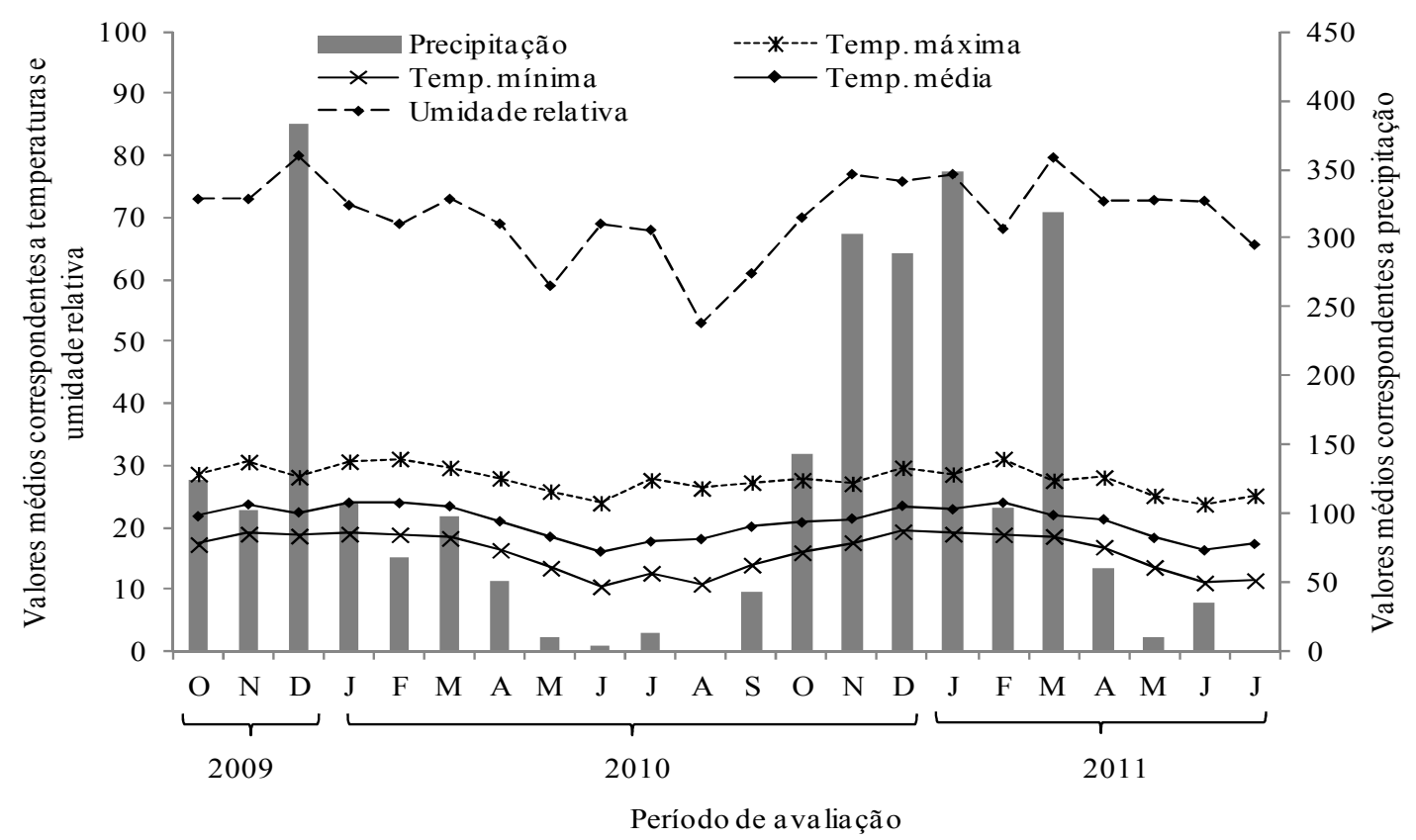

Fonte: Elaboração dos autores.

Tabela 1. Análise do solo na profundidade de 0-20 cm antes da aplicação dos tratamentos, em junho de 2009, no pomar de tangerineira 'Ponkan' em Perdões, $\mathrm{MG}^{1}$.

\begin{tabular}{|c|c|c|c|c|c|c|c|c|c|}
\hline $\mathrm{pH}$ & $\mathrm{P}$ & $\mathrm{K}$ & $\mathrm{Ca}$ & $\mathrm{Mg}$ & $\mathrm{Al}$ & $\mathrm{H}+\mathrm{Al}$ & SB & $\mathrm{t}$ & $\mathrm{T}$ \\
\hline $\mathrm{H}_{2} \mathrm{O}$ & \multicolumn{2}{|c|}{---mg dm${ }^{-3}--$} & & \multicolumn{4}{|c|}{$---\mathrm{cmol}_{c} \mathrm{dm}^{-3}-$} & \\
\hline 5,0 & 3,1 & 104,0 & 1,1 & 0,4 & 0,8 & 5,2 & 1,7 & 2,5 & 6,9 \\
\hline V & $\mathrm{m}$ & $\mathrm{MO}$ & Prem & $\mathrm{Zn}$ & $\mathrm{Fe}$ & $\mathrm{Mn}$ & $\mathrm{Cu}$ & B & $\mathrm{S}$ \\
\hline ------ & $-\%$ & ---- & & & 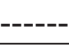 & $-m g d i$ & 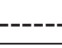 & & \\
\hline 25,2 & 31,1 & 2,0 & 11,7 & 0,70 & 72,3 & 29,3 & 6,1 & 0,7 & 75,0 \\
\hline
\end{tabular}

${ }^{1}$ Análise realizada no Laboratório de Fertilidade do Solo do Departamento de Ciência do Solo da Universidade Federal de Lavras, Lavras, MG, Brasil

$\mathrm{P}-\mathrm{K}-\mathrm{Fe}-\mathrm{Zn}-\mathrm{Mn}-\mathrm{Cu}-$ Extrator Melich 1

$\mathrm{Ca}-\mathrm{Mg}-\mathrm{Al}-$ Extrator $\mathrm{KCl} 1 \mathrm{~mol} \mathrm{~L}{ }^{-1}$

$\mathrm{H}+\mathrm{Al}-$ Extrator SMP

$\mathrm{B}$ - Extrator água quente

$\mathrm{S}$ - Extrator - Fosfato monocálcico em ácido acético

Matéria Orgânica (MO) - Oxidação: $\mathrm{Na}_{2} \mathrm{Cr}_{2} \mathrm{O}_{7} 4 \mathrm{~N}+\mathrm{H}_{2} \mathrm{SO}^{4} 10 \mathrm{~N}$.

Fonte: Elaboração dos autores.

A adubação de produção do pomar comercial foi realizada anualmente com aplicação de $300 \mathrm{~g}$ de superfosfato simples $\left(20 \%\right.$ de $\left.\mathrm{P}_{2} \mathrm{O}_{5}\right)$ e $20 \mathrm{~L}$ de esterco de curral curtido por planta em agosto, depois da colheita. Nesse período também foi aplicado 2,5\% de oxicloreto de cobre por hectare diluído em tanque de $600 \mathrm{~L}$ de água. Em julho de 2010 aplicaram-se duas toneladas por hectare de calcário dolomítico (PRNT de 87\%) em superfície na área total.

Em cada ano foram aplicados $2 \mathrm{~kg}$ de adubo formulado $\mathrm{N}-\mathrm{P}_{2} \mathrm{O}_{5}-\mathrm{K}_{2} \mathrm{O}$ (20-05-20) por planta, 
dividida em quatro aplicações, com intervalo de 40 dias, com início na floração (outubro/novembro). Também foram realizadas quatro pulverizações foliares com 1,5 L por hectare do fertilizante foliar Citrolino $^{\circledR}(10,0 \%$ de $\mathrm{N} ; 3,0 \%$ de $\mathrm{S} ; 1,0 \%$ de $\mathrm{Mg}$; 3,0\% de $\mathrm{Zn} ; 2,0 \%$ de $\mathrm{Mn} ; 0,1 \%$ de $\mathrm{Mo} ; 8,0 \%$ de $\mathrm{Ca}$ e $0,5 \%$ de B), diluído em tanque de $600 \mathrm{~L}$ de água, a cada 40 dias a partir de novembro.

O delineamento experimental foi em blocos casualizados, com parcela subdividida no tempo, sendo a parcela quatro doses de granulado bioclástico $\left(0,0 ; 0,3 ; 0,6\right.$ e $1,2 \mathrm{~kg}$ planta $\left.^{-1}\right)$ e a subparcela os dois anos de avaliação (2010 e 2011). Foram utilizadas seis repetições e quatro plantas por parcela, com as duas plantas centrais constituindo a parcela útil. No primeiro ano (2010) essas doses foram parceladas em dezembro de 2009 e em março de 2010 e no segundo ano (2011) repetiu-se a aplicação das mesmas doses parceladas em dezembro de 2010 e março de 2011.

O granulado bioclástico utilizado foi da marca comercial Alfertil ${ }^{\circledR}$ com 46,3\% de CaO; 33,1\% de $\mathrm{Ca} ; 4,2 \%$ de $\mathrm{MgO} ; 2,5 \%$ de $\mathrm{Mg} ; 92,6 \%$ de PRNT; 2,0 $\mathrm{mg} \mathrm{kg}^{-1}$ de $\mathrm{Cu} ; 259,9 \mathrm{mg} \mathrm{kg}{ }^{-1}$ de $\mathrm{Mn} ; 10,9 \mathrm{mg}$ $\mathrm{kg}^{-1}$ de Zn; 2,6 $\mathrm{g} \mathrm{kg}^{-1}$ de Fe; 101,9 mg kg-1 de B; $0,78 \mathrm{~g} \mathrm{~kg}^{-1}$ de $\mathrm{P}$ e $6,90 \mathrm{~g} \mathrm{~kg}^{-1}$ de $\mathrm{K}$. As análises desse produto foram feitas no Laboratório de Análise de Corretivos e no Laboratório de Análise de Fertilizantes, do Departamento de Química DQI, da Universidade Federal de Lavras - UFLA, Lavras, MG, Brasil.

Nas colheitas, em junho de 2010 e em junho de 2011, avaliou-se a produção de frutas (caixa de 22 $\mathrm{kg}$ por planta). Nessas épocas, com o objetivo de verificar o efeito da aplicação dos tratamentos sobre o comportamento nutricional das plantas, foram retiradas amostras foliares em ramos produtivos, coletando-se folhas maduras, terceira e quarta folha a partir das frutas, num total de 48 folhas por parcela, com adaptação do método utilizado por Santos e Castro (2001) e enviadas para o Laboratório de Análise Foliar do Departamento de
Química, da Universidade Federal de Lavras, para a quantificação dos teores foliares de nutrientes $(\mathrm{N}, \mathrm{P}$, $\mathrm{K}, \mathrm{Ca}, \mathrm{Mg}$ e S) de acordo com metodologia proposta por Malavolta, Vitti e Oliveira (1997).

Para avaliar a qualidade foram colhidas aleatoriamente vinte frutas por parcela localizada na parte mediana da copa, em junho de 2010 e junho de 2011, mediante a determinação do diâmetro transversal (mm), diâmetro longitudinal (mm), massa (g), acidez titulável (\%), teores de sólidos solúveis ( ${ }^{\circ}$ Brix) e ratio (determinado pela relação sólidos solúveis/acidez titulável). A acidez titulável foi avaliada a partir do suco das frutas titulado com hidróxido de sódio $(\mathrm{NaOH})$ 0,1 M, e fenolftaleína como indicador, expressando-se os resultados em \% de ácido cítrico no suco de acordo com as normas estabelecidas pela AOAC (2002). Os sólidos solúveis foram determinados com refratômetro digital de campo ajustado seguindo a recomendação do Instituto Adolfo Lutz (1985).

Foram retiradas quatro amostras simples de solo em cada parcela útil na projeção da copa, na profundidade de 0 a $20 \mathrm{~cm}$, em junho de 2011, para formar uma amostra composta. As amostras compostas de cada parcela foram enviadas para o Laboratório de Fertilidade do Solo do Departamento de Ciência do Solo da Universidade Federal de Lavras para análise dos atributos químicos apresentados na tabela 2 .

Os dados obtidos foram submetidos à análise de variância e a regressão polinomial a 5\% de significância.

\section{Resultados e Discussão}

Não houve diferença entre os parâmetros da análise de solo avaliados com a aplicação do granulado bioclástico nas plantas (Tabela 2), que pode ser atribuída à elevação da saturação por bases promovida pela aplicação de calcário na área em julho de 2010. Na análise foliar no ano de 2010 foi constatado aumento de $4,1 \%$ nos teores de $\mathrm{N}$ com a 
dose estimada de $0,73 \mathrm{~kg}$ de granulado bioclástico por planta e no ano de 2011 houve aumento de $4,7 \%$ dos teores de $\mathrm{N}$ foliar nas tangerineiras que receberam $1,2 \mathrm{~kg}$ em relação às plantas sem aplicação (Figura 2A).

Tabela 2. Análise de solo na profundidade de $0-20 \mathrm{~cm}$, em função do granulado bioclástico (GB) por planta $(\mathrm{kg})$ no final do experimento, em junho de 2011, em Perdões, $\mathrm{MG}^{2}$.

\begin{tabular}{|c|c|c|c|c|c|c|c|c|c|c|}
\hline \multirow[t]{2}{*}{ GB } & $\mathrm{pH}$ & $\mathrm{P}$ & K & $\mathrm{Ca}$ & $\mathrm{Mg}$ & $\mathrm{Al}$ & $\mathrm{H}+\mathrm{Al}$ & SB & $\mathrm{t}$ & $\mathrm{T}$ \\
\hline & $\mathrm{H}_{2} \mathrm{O}$ & \multicolumn{2}{|c|}{-----mg dm³---- } & & 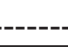 & $----\mathrm{cr}$ & $\mathrm{dm}^{-3}-$ & & & -- \\
\hline 0,0 & 7,7 & 2,7 & 62,5 & 5,0 & 1,9 & 0,0 & 1,5 & 7,1 & 7,1 & 8,6 \\
\hline 0,3 & 7,5 & 5,9 & 103,5 & 5,0 & 1,5 & 0,0 & 1,4 & 6,8 & 6,8 & 8,2 \\
\hline 0,6 & 7,5 & 2,9 & 100,0 & 4,6 & 1,5 & 0,0 & 1,6 & 6,4 & 6,4 & 8,0 \\
\hline 1,2 & 7,6 & 4,7 & 118,5 & 4,6 & 1,6 & 0,0 & 1,5 & 6,6 & 6,6 & 8,1 \\
\hline \multirow[t]{2}{*}{ GB } & V & $\mathrm{m}$ & MO & Prem & $\mathrm{Zn}$ & $\mathrm{Fe}$ & $\mathrm{Mn}$ & $\mathrm{Cu}$ & B & $\mathrm{S}$ \\
\hline & \multicolumn{3}{|c|}{------------ \%"--------- } & & & & $\mathrm{mg} \mathrm{dn}$ & & & -- \\
\hline 0,0 & 82,0 & 0,0 & 2,9 & 10,1 & 5,0 & 59,0 & 88,0 & 9,0 & 0,4 & 10,0 \\
\hline 0,3 & 83,0 & 0,0 & 3,5 & 9,6 & 5,0 & 51,0 & 72,0 & 11,0 & 0,4 & 9,0 \\
\hline 0,6 & 80,0 & 0,0 & 3,1 & 11,0 & 5,0 & 55,0 & 81,0 & 13,0 & 0,3 & 14,0 \\
\hline 1,2 & 81,0 & 0,0 & 2,8 & 10,1 & 5,0 & 56,0 & 92,0 & 9,0 & 0,3 & 15,0 \\
\hline
\end{tabular}

Médias em cada atributo do solo não diferiram estatisticamente a $5 \%$ de significância pelo teste de ' $F$ '.

${ }^{2}$ Análises realizadas no Laboratório de Fertilidade do Solo do Departamento de Ciência do Solo da Universidade Federal de Lavras, Lavras, Minas Gerais, Brasil

$\mathrm{P}-\mathrm{K}-\mathrm{Fe}-\mathrm{Zn}-\mathrm{Mn}-\mathrm{Cu}-$ Extrator Melich 1

$\mathrm{Ca}-\mathrm{Mg}-\mathrm{Al}-$ Extrator $\mathrm{KCl} 1 \mathrm{~mol} \mathrm{~L}^{-1}$

$\mathrm{H}+\mathrm{Al}-$ Extrator SMP

$\mathrm{B}$ - Extrator água quente

$\mathrm{S}$ - Extrator - Fosfato monocálcico em ácido acético

Matéria Orgânica (MO) - Oxidação: $\mathrm{Na}_{2} \mathrm{Cr}_{2} \mathrm{O}_{7} 4 \mathrm{~N}+\mathrm{H}_{2} \mathrm{SO}^{4} 10 \mathrm{~N}$.

Fonte: Elaboração dos autores.

Para os teores foliares de P (Figura 2B) observouse aumento linear no ano de 2010 e comportamento quadrático em 2011, com maior teor averiguado na dose estimada $0,5 \mathrm{~kg}$ de granulado bioclástico por planta. A elevação nos teores foliares de $\mathrm{N}$ e de $\mathrm{P}$ parece estar associada ao efeito benéfico das algas calcárias no solo em ativar o desenvolvimento das bactérias autotróficas responsáveis pelo processo de nitrificação e à melhoria na disponibilidade de $\mathrm{P}$, respectivamente, conforme relatado por Dias (2000).
Em 2010 verificou-se que a aplicação de 1,2 $\mathrm{kg}$ de granulado bioclástico por planta promoveu incremento de $6,7 \%$ nos teores de $\mathrm{K}$ nas folhas e no ano de 2011 foi observada redução em função do aumento das doses de granulado bioclástico (Figura 2C). Esse comportamento pode ser explicado devido à translocação desse nutriente para as frutas, pois a amostragem foliar foi realizada no período da colheita. Dessa maneira, a variação nos teores foliares de $\mathrm{K}$ pode estar relacionada com a diferença na produção entre os anos, visto que em 2010 não houve diferença entre a produção das plantas em função da aplicação do granulado bioclástico, enquanto em 2011 a produção foi duas vezes maior que a testemunha com a utilização de $0,77 \mathrm{~kg}$ de granulado bioclástico por planta (Figura 3). 
Figura 2. Teores foliares de nitrogênio (A), fósforo (B), potássio (C), cálcio (D), magnésio (E) e enxofre (F) em tangerineiras 'Ponkan' em função do granulado bioclástico aplicado por planta em Perdões, MG, nos anos de 2010 e 2011.
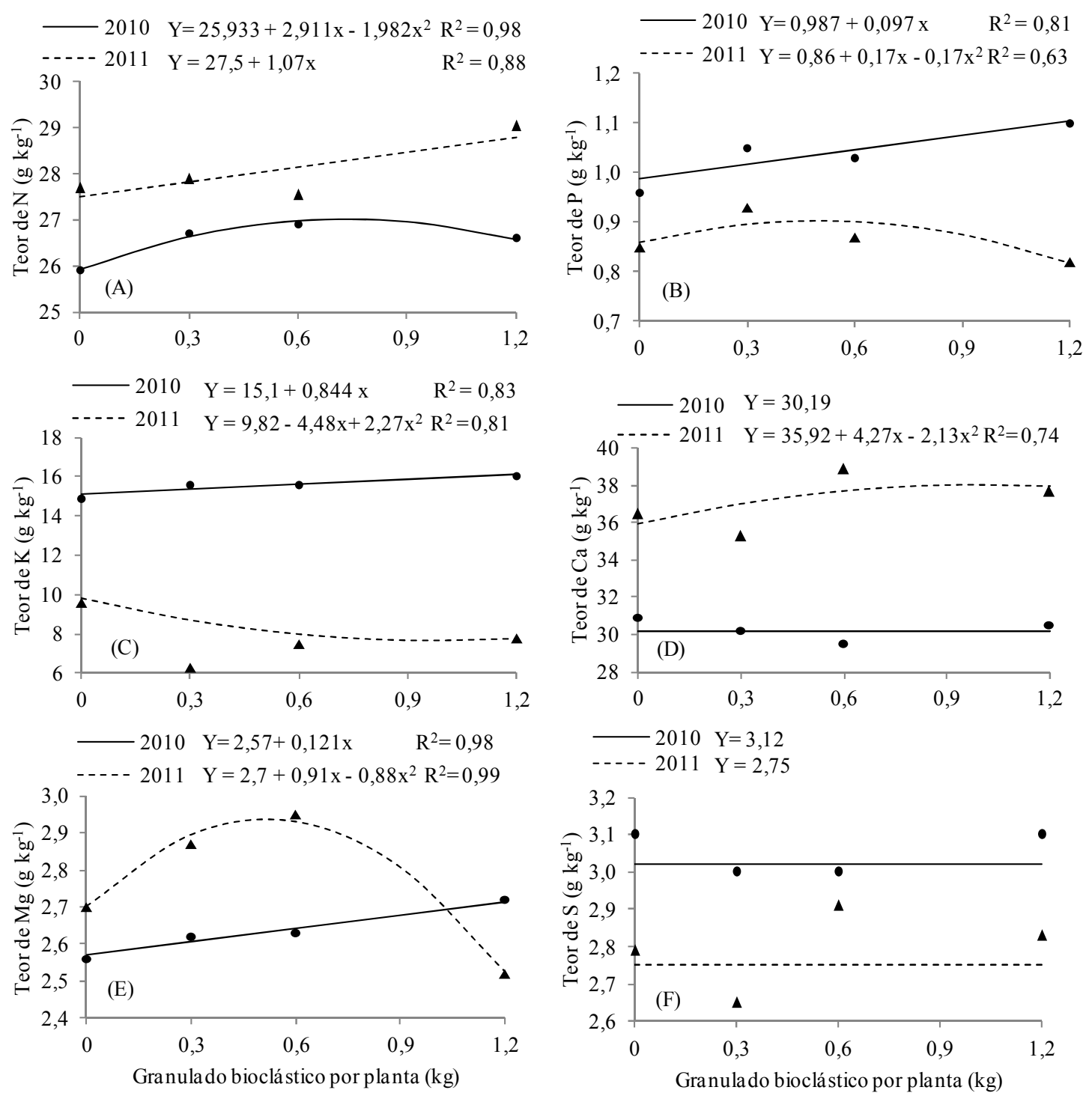

Fonte: Elaboração dos autores.

Foi averiguado que os teores de Ca (Figura 2D) permaneceram semelhantes e mais baixos em 2010 e que em 2011 foi incrementado até a dose estimada de $1 \mathrm{~kg}$ planta $^{-1}$ de granulado bioclástico. A diferença entre os anos é atribuída à aplicação de calcário que foi feita na área total em julho de 2010, por promover a redução da acidez do solo e fornecer $\mathrm{Ca}$ às plantas (FIDALSKI; AULER, 2008). A aplicação do granulado bioclástico promoveu incremento linear nos teores foliares de $\mathrm{Mg}$ das tangerineiras no ano de 2010 (Figura 2E). Entretanto, no ano de 2011 foi encontrado maior teor foliar de $\mathrm{Mg}$ com a dose estimada de $0,52 \mathrm{~kg}$ por planta ${ }^{-1}$. A elevação dos teores foliares de nutrientes com aplicação de 
granulado bioclástico no solo também foi verificada por Melo e Furtini Neto (2003) em feijoeiro, devido ao aumento nos teores de $\mathrm{Ca}$ e $\mathrm{Mg}$ trocável no solo, ocasionado pela alga Lithothamnium, possibilitando o aumento de absorção pelo sistema radicular da cultura.

Figura 3. Produção de tangerineira 'Ponkan' em função do granulado bioclástico aplicado por planta em Perdões, MG, nos anos de 2010 e 2011.

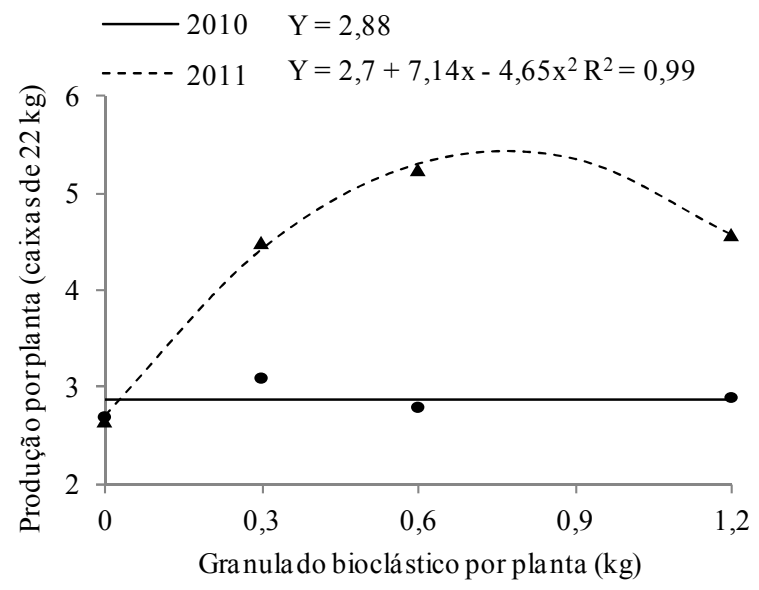

Fonte: Elaboração dos autores.

Foram constatados teores foliares médios de $\mathrm{S}$ de $3,1 \mathrm{~g} \mathrm{~kg}^{-1}$ em 2010 e de $2,7 \mathrm{~g} \mathrm{~kg}^{-1}$ em 2011 independentes da dose aplicada de granulado bioclástico (Figura 2F). Esses teores de $\mathrm{S}$ foram superiores aos encontrados (de 1,3 a 2,4 $\mathrm{g} \mathrm{kg}^{-1}$ ) por Santos e Castro (2001) em folhas de tangerineiras 'Ponkan', também no período de colheita de frutas.

Para as características físicas das frutas foi observado que a aplicação de 1,2 kg de granulado bioclástico no ano de 2010 promoveu aumento de $6,6 \%, 8,0 \%$ e $17,7 \%$ em relação às plantas sem aplicação do produto, no diâmetro transversal, diâmetro longitudinal e massa das frutas, respectivamente (Figuras 4A, 4B e 4C). Já para o ano de 2011 constataram-se aumentos de 5,2\% no diâmetro transversal e de 5,9\% no diâmetro longitudinal com a dose estimada de $0,8 \mathrm{~kg}$ de granulado bioclástico. Para a massa das frutas houve aumento de 8,4\% com a aplicação de $1 \mathrm{~kg}$ de granulado bioclástico por planta em 2011.

O aumento no tamanho das frutas com a aplicação do granulado bioclástico pode ser atribuído à maior disponibilidade de nutrientes, notadamente o $\mathrm{K}$ que em tangerineiras possui efeito importante, pois plantas deficientes produzem frutas de tamanho reduzido, o que deprecia o valor de comercialização (MATTOS JÚNIOR et al., 2004). A redução observada nos teores foliares de $\mathrm{K}$ no período de colheita com a aplicação do granulado bioclástico no ano de 2011 (Figura 2C) pode ter ocorrido devido à translocação para as frutas devido à maior produção (Figura 3 ) e ao maior tamanho das tangerinas (Figuras 4A, 4B e 4C).

O resultado da aplicação de granulado bioclástico nesse trabalho se assemelha aos aumentos da produtividade e da massa de frutas de laranjeiras obtidos por Quaggio, Mattos Júnior e Boaretto (2011) com a elevação da adubação potássica, confirmando que as algas calcárias do gênero Lithothamnium disponibilizam maiores quantidades de nutrientes para as plantas (DIAS, 2000), visto que não constatou-se diferença nas características químicas do solo em função dos tratamentos aplicados (Tabela 2). 
Figura 4. Diâmentro transversal (A), diâmetro longitudinal (B), massa (C), sólidos solúveis (D), acidez titulável (E) e ratio (F) de frutas de tangerineira 'Ponkan' em função do granulado bioclástico aplicado por planta em Perdões, MG, nos anos de 2010 e 2011.
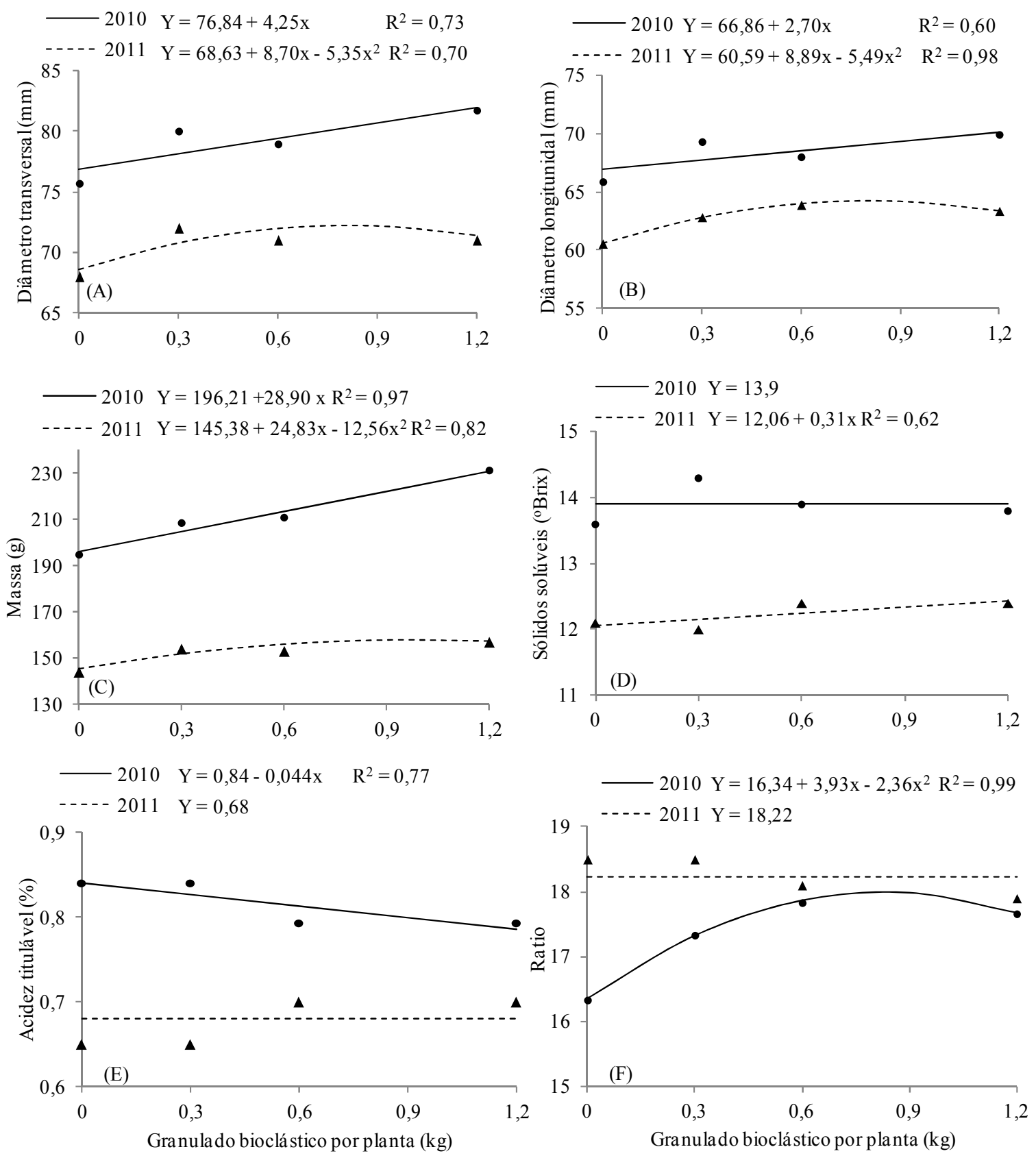

Fonte: Elaboração dos autores.

Em relação às características químicas das frutas, verificaram-se maiores teores de sólidos solúveis (13,9 Brix) no ano de 2010, sem influência da utilização do granulado boclástico (Figura 4D).
Entretanto, no ano de 2011, houve incremento 3,1\% nos sólidos solúveis com a aplicação de 1,2 kg de granulado bioclástico por tangerineira em relação a frutas de plantas do tratamento testemunha (Figura 
4D). O menor teor de sólidos solúveis em 2011 pode ser explicado pela maior precipitação pluviométrica ocorrida próxima à colheita desse ano (Figura 1) promovendo efeito 'diluição' nas frutas. Esse comportamento também foi relatado por Moreira et al. (2013) em tangerinas 'Ponkan' colhidas em períodos de maior ocorrência de chuva próxima à maturação.

Foi observada redução linear da acidez titulável no ano de 2010 em função da aplicação de granulado bioclástico e valores semelhantes no ano de 2011 (Figura 4E). A redução da acidez pode ser explicada em decorrência do aumento do tamanho das tangerinas (VILAS BOAS et al., 1998), pois frutas de maior tamanho apresentam estádio de maturação fisiológica mais avançado, resultando na utilização de ácidos orgânicos, principalmente o ácido cítrico, como substrato na respiração ou na transformação em açúcares (CHITARRA; CHITARRA, 2005).

Devido o ratio ser calculado pela relação sólidos solúveis/ acidez titulável foi averiguado elevação em 2010 de $10 \%$ com a dose estimada de $0,83 \mathrm{~kg}$ de granulado bioclástico e em 2011 valores semelhantes de 18,22 (Figura 4F). Aumento nos sólidos solúveis e no ratio e redução de acidez titulável nas frutas de pitaia foram constatados por Moreira et al. (2011b) com aplicação de granulado bioclástico associado à matéria orgânica.

\section{Conclusões}

A aplicação de granulado bioclástico aumentou os teores foliares de $\mathrm{N}, \mathrm{P}, \mathrm{Ca}$ e $\mathrm{Mg}$ na época de colheita.

Os teores de $\mathrm{K}$ nas folhas das tangerineiras 'Ponkan' na época de colheita reduziram com o aumento da dose de granulado bioclástico por planta.

A dose de $0,8 \mathrm{~kg}$ de granulado bioclástico por planta favoreceu a produção e melhorou a qualidade das frutas de tangerineira 'Ponkan'.

\section{Referências}

ANUÁRIO DA AGRICULTURA BRASILEIRA AGRIANUAL. São Paulo: Instituto FNP, 2011. p. 275276.

ASSOCIATION OF OFFICIAL ANALYTICAL CHEMISTRY - AOAC. Official methods of analysis of the Association of Official Analytical Chemistry. $17^{\text {th }}$ ed. Washington: AOAC, 2002. $1115 \mathrm{p}$.

ARAÚJO, P. O. L. C.; GONÇALVES, F. C.; RAMOS, J. D.; CHALFUN, N. N. J.; CARVALHO, G. J. Crescimento e percentual de emergência de plântulas de citrumeleiro 'Swingle' em função dos substratos e das doses de corretivo à base de Lithothamnium, após cem dias da semeadura. Ciência e Agrotecnologia, Lavras, v. 31, n. 4, p. 982-988, 2007.

CHITARRA, M. I. F.; CHITARRA, A. B. Pós-colheita de frutos e hortaliças: fisiologia e manuseio. 2. ed. Lavras: UFLA, 2005. $785 \mathrm{p}$.

CRUZ, M. C. M.; HAFEL, O. M.; RAMOS, J. D.; RAMOS, P. S. Revista Brasileira de Fruticultura, Jaboticabal, v. 30, n. 2, p. 471-475, 2008.

CRUZ, M. C. M.; MOREIRA, R. A. Production regularity of 'Ponkan' mandarin trees submitted to chemical thinning. Semina: Ciências Agrárias, Londrina, v. 33, n. 6, p. 2163-2172, 2012.

DIAS, G. T. M. Granulados bioclásticos - algas calcárias. Revista Brasileira de Geofísica, São Paulo, v. 18, n. 13, p. 307-318, 2000.

FIDALSKI, J.; AULER, P. A. M. Alterações químicas temporais nas faixas de adubação e entrelinhas do pomar, nutrição e produção de laranja após calagem superficial. Revista Brasileira de Ciência do Solo, Viçosa, v. 32, n. 2, p. 689-696, 2008.

HAFLE, O. M.; SANTOS, V. A.; RAMOS, J. D.; CRUZ, M. C. M.; MELO, P. C. Produção de mudas de mamoeiro utilizando Bokashi e Lithothamnium. Revista Brasileira de Fruticultura, Jaboticabal, v. 31, n. 1, p. 245-251, 2009.

INSTITUTO ADOLFO LUTZ - IAL. Normas analíticas: métodos químicos e físicos para análises de alimentos. 3. ed. São Paulo: IAL, 1985. v. 1, 533 p.

KOLLER, O. C. Citricultura: cultura de tangerineiras. Porto Alegre: Editora Rígel, 2009. 400 p.

MALAVOLTA, E.; VITTI, G. C.; OLIVEIRA, S. A. Avaliação do estado nutricional das plantas: princípios e aplicações. 2. ed. Piracicaba: Associação Brasileira para Pesquisa do Fosfato, 1997. 238 p. 
MATTOS JÚNIOR, D.; QUAGGIO, J. A.; CANTARELlA, H.; CARVALHO, S. A. Superfícies de resposta do tangor 'Murcott' à fertilização com N, P e K. Revista Brasileira de Fruticultura, Jaboticabal, v. 26, n. 1, p. 164-167, 2004.

MELO, P. C.; FURTINI NETO, A. E. Avaliação do Lithothamnium como corretivo da acidez do solo e fonte de nutrientes para o feijoeiro. Ciência e Agrotecnologia, Lavras, v. 27, n. 3, p. 508-519 2003.

MOREIRA, R. A.; RAMOS, J. D.; ARAÚJO, N. A.; MARQUES, V. B. Produção e qualidade de frutos de pitaia-vermelha com adubação orgânica e granulado bioclástico. Revista Brasileira de Fruticultura, Jaboticabal, v. 33, p. 762-766, 2011b. Suplemento 1.

MOREIRA, R. A.; RAMOS, J. D.; MARQUES, V. B.; ARAúJo, N. A.; MELO, P. C. Crescimento de pitaia vermelha com adubação orgânica e granulado bioclástico. Ciência Rural, Santa Maria, v. 41, n. 5, p. 785-788, 2011a.

MOREIRA, R. A.; RAMOS, J. D.; CRUZ, M. C. M.; PANTOJA, L. A.; SANTOS, A. S. Leaf carbohydrates in 'Ponkan' mandarin fruit quality under chemical thinning. Acta Scientiarum. Agronomy, Maringá, v. 35, n. 3, p. 349-356, 2013.

QUAGGIO, J. A.; MATTOS JUNIOR, D.; BOARETTO, R. M. Sources and rates of potassium for sweet orange production. Scientia Agricola, Piracicaba, v. 68, n. 3, p. 369-375, 2011.
RAMOS, J. D.; CRUZ, M. C. M.; PASQUAL, M.; HAFLE, O.; RAMOS, P. S.; ROSSI, E. P. Etephon no raleio de tangerinas 'Ponkan. Ciência Rural, Santa Maria, v. 39, n. 1, p. 236-240, 2009.

SANTOS, A. C. P.; CASTRO, P. R. C. Desbaste químico em tangerineira 'Ponkan' sobre o nível de carboidratos e a composição mineral das folhas. Laranja, Cordeirópolis, v. 22, n. 1, p. 93-112, 2001.

SANTOS, C. H.; GRASSI FILHO, H.; SANTOS, J. C.; PENTEADO, B. B. Fertilidade do solo e nutrição de tangerineiras Ponkan manejados com resíduos sólidos e adubação química. Revista Brasileira de Engenharia Agrícola e Ambiental, Campina Grande, v. 15, n. 1, p. 75-83, 2011.

SOUZA, H. A.; RAMOS, J. D.; MELO, P. C.; HAFLE, O. M.; RODRIGUES, H. C. A.; SANTOS, V. A. Avaliação de doses e produtos corretores da acidez em variáveis biométricas na produção de mudas de maracujazeiro. Acta Scietiarum. Agronomy, Maringá, v. 31, n. 4, p. 607612, 2009.

VILAS BOAS, E. V. B.; REIS, J. M. R.; LIMA, L. C.; CHITARRA, A. B.; RAMOS, J. D. Influência do tamanho sobre a qualidade de tangerinas, variedade Ponkan, na cidade de Lavras-MG. Revista da Universidade de Alfenas, Alfenas, v. 4, n. 2, p. 131-135, 1998. 